E3S Web of Conferences 1, 05004 (2013)

DOI: $10.1051 / \mathrm{e} 3$ sconf/20130105004

(C) Owned by the authors, published by EDP Sciences, 2013

\title{
Interaction of heavy metals with dehydrated carbon
}

\author{
E. I. El-Shafey ${ }^{1}$ \\ ${ }^{1}$ Department of Chemistry, College of Science, Sultan Qaboos University, P.O. Box 36 - Alkhodh 123, Muscat, Oman. \\ dr_el_shafey2004@yahoo.co.uk
}

\begin{abstract}
Dehydrated carbon material was prepared from date palm leaflets via sulphuric acid treatment. The acid causes dehydration via the removal of water. In addition it causes oxidation to the dehydrated carbon surface. The carbon was tested for the removal of $\mathrm{Pb}^{2+}, \mathrm{Zn}^{2+}, \mathrm{Cu}^{2+}, \mathrm{Co}^{2+}, \mathrm{Ag}^{+}, \mathrm{Pd}^{2+}$ and $\mathrm{Hg}^{2+}$ from aqueous solution in terms of different $\mathrm{pH}$, time and concentrations and temperature. Optimum $\mathrm{pH}$ was found to be in the range of 3-5 for the metals under investigation. Sorption of $\mathrm{Pb}^{2+}, \mathrm{Zn}^{2+}, \mathrm{Cu}^{2+}, \mathrm{Co}^{2+}$ was found fast, reaching equilibrium within $\sim 2 \mathrm{hr}$ while the sorption of $\mathrm{Ag}^{+}, \mathrm{Pd}^{2+}$ and $\mathrm{Hg}^{2+}$ (nitrate and chloride media) was slow and required $\sim 80 \mathrm{hr}$ to reach equilibrium. Activation energy, $E_{a}$, for the sorption of $\mathrm{Pb}^{2+}, \mathrm{Zn}^{2+}, \mathrm{Cu}^{2+}, \mathrm{Co}^{2+}$ was $<17$ $\mathrm{kJ} / \mathrm{mol}$ indicating a diffusion controlled ion exchange process, however, for $\mathrm{Ag}^{+}, \mathrm{Pd}^{2+}$ and $\mathrm{Hg}^{2+}$ sorption, $E_{a}$ was $>40 \mathrm{~kJ} / \mathrm{mol}$ indicating a chemically controlled process. Equilibrium sorption capacity was much higher for $\mathrm{Ag}^{+}, \mathrm{Pd}^{2+}$ and $\mathrm{Hg}^{2+}$ than for $\mathrm{Pb}^{2+}, \mathrm{Zn}^{2+}, \mathrm{Cu}^{2+}, \mathrm{Co}^{2+}$ with increased uptake, for both metals, by rising the temperature $\left(25-45{ }^{\circ} \mathrm{C}\right)$. Scanning electron microscopy, X-ray diffraction and energy dispersive spectroscopy showed that $\mathrm{Ag}^{+}$and $\mathrm{Pd}^{2+}$ were reduced to their respective elemental states. For $\mathrm{Hg}^{2+}$, reduction took place to elemental mercury from nitrate media and to $\mathrm{Hg}_{2} \mathrm{Cl}_{2}$ from the chloride media. However, no reduction processes were involved in the sorption of $\mathrm{Pb}^{2+}, \mathrm{Zn}^{2+}, \mathrm{Cu}^{2+}, \mathrm{Co}^{2+}$.
\end{abstract}

Key words: heavy metals, sorption, reduction, dehydrated carbon

\section{Introduction}

During the past few years, there has been an increasing interest in the determination of concentrations, sources and fluxes of heavy metals in the environment. There is a widespread concern with the effects of technological advances on the chemical composition of the total environment including streams, lakes, oceans, atmosphere and soil systems. Existing physical and chemical technologies for the removal of heavy metals from wastewater including electro-coagulation, chemical precipitation, membrane filtration and reverse osmosis are either too expensive or not appropriate for the treatment of dilute solutions. Adsorption technologies provide a cheaper and effective option. In this paper, dehydrated carbon via sulfuric acid treatment was prepared from date palm leaflets, an abundant agricultural waste in Oman and the Gulf States and was investigated for the removal of $\mathrm{Pb}^{2+}, \mathrm{Zn}^{2+}, \mathrm{Cu}^{2+}, \mathrm{Co}^{2+}, \mathrm{Ag}^{+}, \mathrm{Pd}^{2+}$ and $\mathrm{Hg}^{2+}$. Dehydrated carbon showed different interaction behaviour for $\mathrm{Ag}^{+}, \mathrm{Pd}^{2+}$ and $\mathrm{Hg}^{2+}$ compared with $\mathrm{Pb}^{2+}$, $\mathrm{Zn}^{2+}, \mathrm{Cu}^{2+}$ and $\mathrm{Co}^{2+}$.

\section{Materials and Methods}

Clean date palm leaflets were chemically-carbonized as by mixing clean air-dried palm leaflets $(20 \mathrm{~g})$ with $80 \mathrm{ml}$ sulfuric acid $(13 \mathrm{M})$. The mixture was heated to $170 \pm 2$ ${ }^{\circ} \mathrm{C}$ in $20 \mathrm{~min}$. with occasional stirring and the temperature was kept in that range of temperature for 25 minutes. After filtration and washing till free from the acid, the carbon was left at $120^{\circ} \mathrm{C}$ in the oven till dryness. The carbon was characterized in terms of surface area, $\mathrm{pHzpc}$, Boehm titration, FTIR, SEM and x-ray diffraction. Solutions of $\mathrm{Pb}^{2+}, \mathrm{Ag}^{+}$were prepared from their respective nitrate form, however $\mathrm{Zn}^{2+}, \mathrm{Cu}^{2+}, \mathrm{Co}^{2+}, \mathrm{Pd}^{2+}$ were prepared from their respective chloride form. $\mathrm{Hg}^{2+}$ solutions were prepared in both nitrate and chloride forms.

Metals were analyzed using AA for $\mathrm{Pb}^{2+}, \mathrm{Zn}^{2+}, \mathrm{Cu}^{2+}$, $\mathrm{Co}^{2+}, \mathrm{Ag}^{+}, \mathrm{Pd}^{2+}$ was analysed using spectrophoptometric iodide method (Bruzzoniti et al., 2003). $\mathrm{Hg}^{2+}$ was analysed using AA with hydride generation.

\section{Results and Discussion}


Sulfuric acid acts as a strong dehydrating and oxidizing agent, carbonizing cellulose and hemicelluloses by the removal of water. Under the carried out conditions of the sorbent preparation, carbonization (via dehydration) with partial oxidation took place to the carbohydrate part (cellulose and hemicelluloses) in addition to partial oxidation and fragmentation to the lignin components (Cox et al. 1999). FTIR showed that the dehydrated carbon possesses $-\mathrm{COOH},-\mathrm{OH}, \mathrm{C}=\mathrm{C}$ and other carbon oxygen species on the surface. Boehm titration showed that $1.28,0.48$ and $0.5 \mathrm{meq} / \mathrm{g}$ correpnoding to carboxyl, lactone and hydroxyl groups on the surface. pHzpc was 2.75. Surface area was measured using nitrogen sorption at $77 \mathrm{~K}$ was $44 \mathrm{~m}^{2} / \mathrm{g}$. such low surface area might be because of the abundant polar functional groups on the surface.

a)

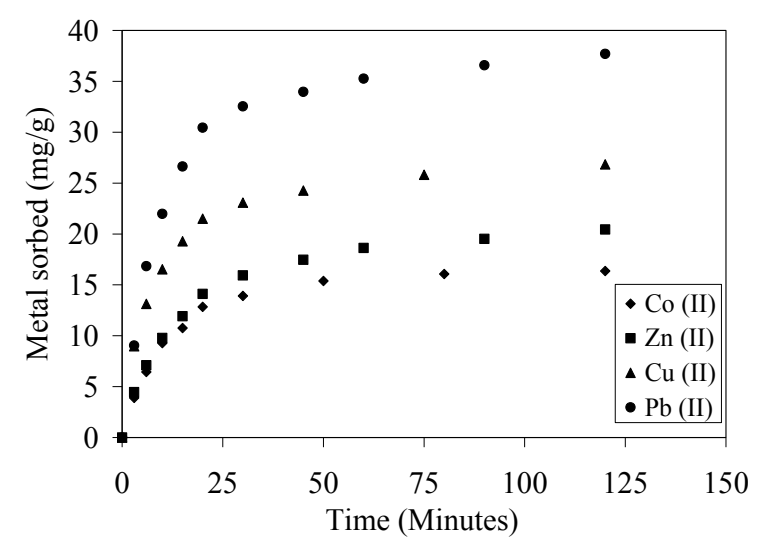

b)

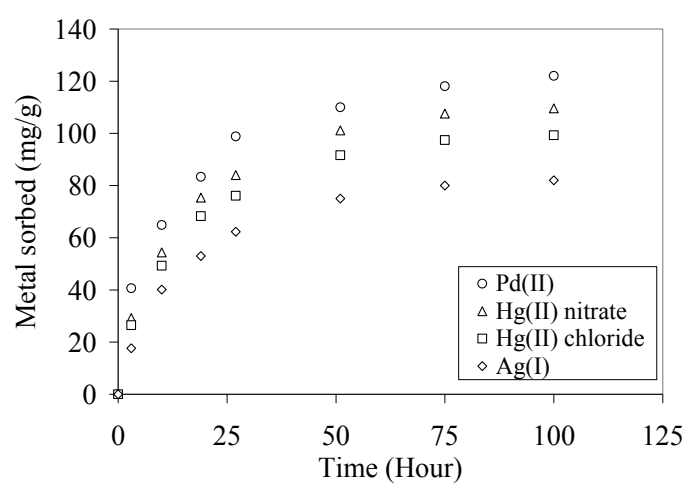

Fig. 1. Sorption kinetics of (A) $\mathrm{Pb}^{2+}, \mathrm{Cu}^{2+}, \mathrm{Zn}^{2+}, \mathrm{Co}^{2+}$ and (b) $\mathrm{Ag}^{+}, \mathrm{Pb}^{2+}$ and $\mathrm{Hg}^{2+}$ on dehydrated carbon at 25 ${ }^{\circ} \mathrm{C}$.

Kinetic studies showed a peculiar behavior for those metals. Sorption of $\mathrm{Pb}^{2+}, \mathrm{Zn}^{2+}, \mathrm{Cu}^{2+}$ and $\mathrm{Co}^{2+}$ shows a much fast kinetics reaching equilibrium within $\sim 2$ hours, however, with less metal uptake. On the other hand, $\mathrm{Ag}^{+}$, $\mathrm{Pd}^{2+}$ and $\mathrm{Hg}^{2+}$ shows a slow kinetics as equilibrium requires $\sim 50$ hours to be reached, with higher metal uptake than that for $\mathrm{Pb}^{2+}, \mathrm{Zn}^{2+}, \mathrm{Cu}^{2+}$ and $\mathrm{Co}^{2+}$ as presented in figure 1. Rising the temperature has shown increased sorption with data fitting pseudo second order model more than pseudo first order model. Ea was found to be in the less than $15 \mathrm{~kJ} / \mathrm{mol}$ for the sorption of $\mathrm{Pb}^{2+}$, $\mathrm{Zn}^{2+}, \mathrm{Cu}^{2+}$ and $\mathrm{Co}^{2+}$, however, Ea was $>40 \mathrm{kj} / \mathrm{mol}$ for the sorption of $\mathrm{Ag}^{+}, \mathrm{Pd}^{2+}$ and $\mathrm{Hg}^{2+}$.

Equilibrium studies showed that sorption of these metals at their respective optimum $\mathrm{pH}$ values showed a good fitting for the Langmuir model than the Freundlich model with much higher sorption capacities for the removal of $\mathrm{Ag}^{+}, \mathrm{Pd}^{2+}$ and $\mathrm{Hg}^{2+}$ than $\mathrm{Pb}^{2+}, \mathrm{Zn}^{2+}, \mathrm{Cu}^{2+}$ and $\mathrm{Co}^{2+}$. Equilibrium $\mathrm{pH}$ was found to be less than initial $\mathrm{pH}$ indicating protons release in solution reflecting ion exchange processes. Scanning electron microscope analysis of metal loaded dehydrated carbon showed the presence pf metallic precipitates of $\mathrm{Ag}, \mathrm{Pd}$ and $\mathrm{Hg}$ (from nitrate media) $\mathrm{Hg}_{2} \mathrm{Cl}_{2}$ crystals (from chloride media) from their respective solutions, Figure 2(a-d). X-ray diffraction confirmed the presence of metallic $\mathrm{Ag}, \mathrm{Pd}$ and $\mathrm{Hg}_{2} \mathrm{Cl}_{2}$ crystals. Energy dispersive spectroscopy confirmed the presence of the metallic state of $\mathrm{Hg}$ from nitrate media. On the other hand, there was no change observed on metal loaded carbons by $\mathrm{Pb}^{2+}, \mathrm{Zn}^{2+}, \mathrm{Cu}^{2+}$ and $\mathrm{Co}^{2+}$ in SEM analysis or X-ray diffraction.

The presence of reduced forms (metallic such as $\mathrm{Ag}, \mathrm{Pd}$ and $\mathrm{Hg}$ or $\mathrm{Hg}_{2} \mathrm{Cl}_{2}$ crystals) on dehydrated carbon surface reflects their reduction. At the same time, dehydrated carbon could not reduce $\mathrm{Pb}^{2+}, \mathrm{Zn}^{2+}, \mathrm{Cu}^{2+}$ and $\mathrm{Co}^{2+}$ to lower oxidation state and ion exchange was the dominating mechanism. This reduction property reflects also the slow kinetics, higher sorption capacity and higher activation energy for the sorption of $\mathrm{Ag}^{+}, \mathrm{Pd}^{2+}$ and $\mathrm{Hg}^{2+}$. Sorbent reuse studies showed that by acid stripping, the carbon can be reused for the sorption of $b^{2+}, \mathrm{Zn}^{2+}$, $\mathrm{Cu}^{2+}$ and $\mathrm{Co}^{2+}$ efficiently, however for the other reducible metals, separation of the precipitated reduced forms of the metal cations is required.

\section{Conclusion}

Dehydrated carbon is capable of reducing $\mathrm{Ag}^{+}, \mathrm{Pb}^{2+}$ and $\mathrm{Hg}^{2+}$ but not $\mathrm{Pb}^{2+}, \mathrm{Cu}^{2+}, \mathrm{Zn}^{2+}$ and $\mathrm{Co}^{2+}$ and this is reflect on the difference in their sorption behavior towards dehydrated carbon. The carbon seems promising in field work applications.

\section{References}

Bruzzoniti, MC, Mucchino, C, Tarasco, E, Sarzanini, C. On-line preconcentration, ion chromatographic separation and spectrophotometric determination of palladium at trace level. J. Chromatogr. A, 2003: 1007: 93-100.

Cox, M., El-Shafey, EI, Pichugin, AA, Appleton, Q. Preparation and characterization of a carbon adsorbent from flax shive by dehydration with sulphuric acid. J. Chem. Technol. Biot. 1999: 74: 1019-1029. 
(a)

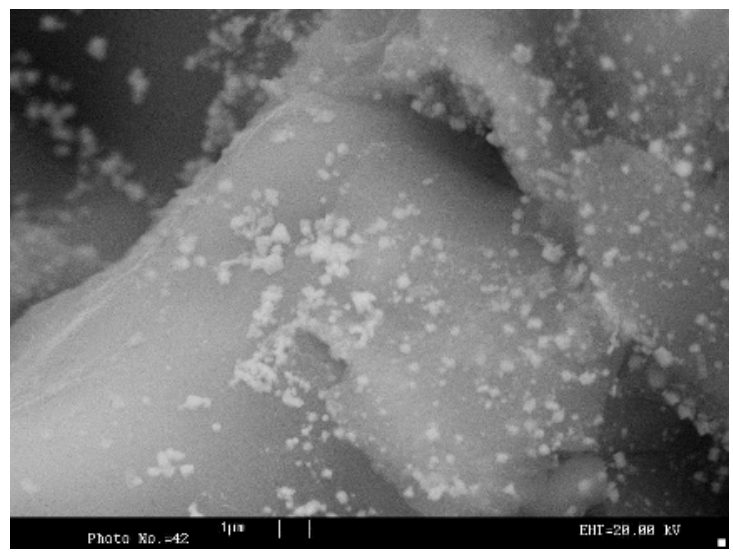

(b)

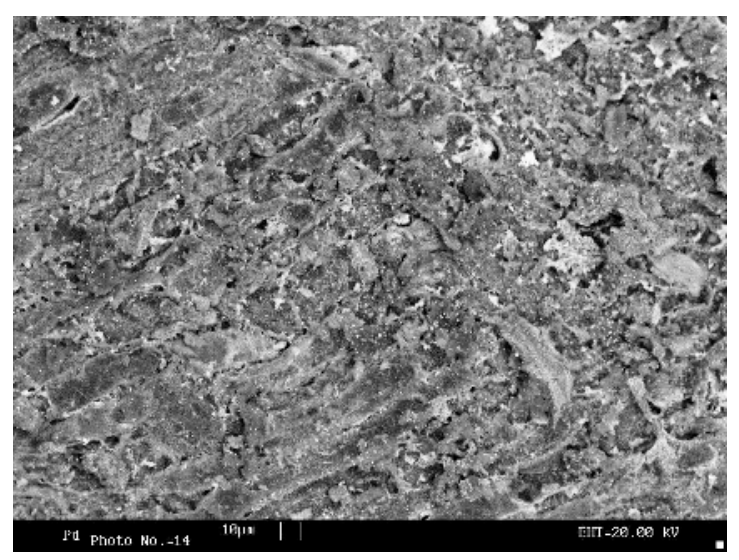

(c)

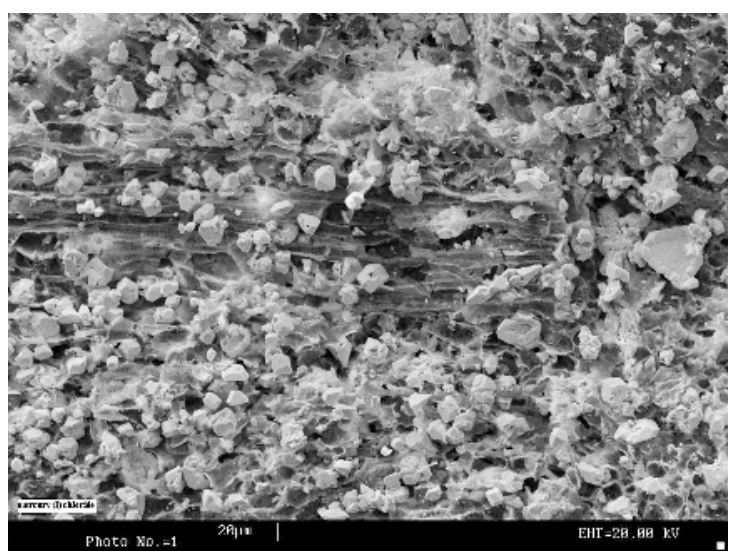

(d)

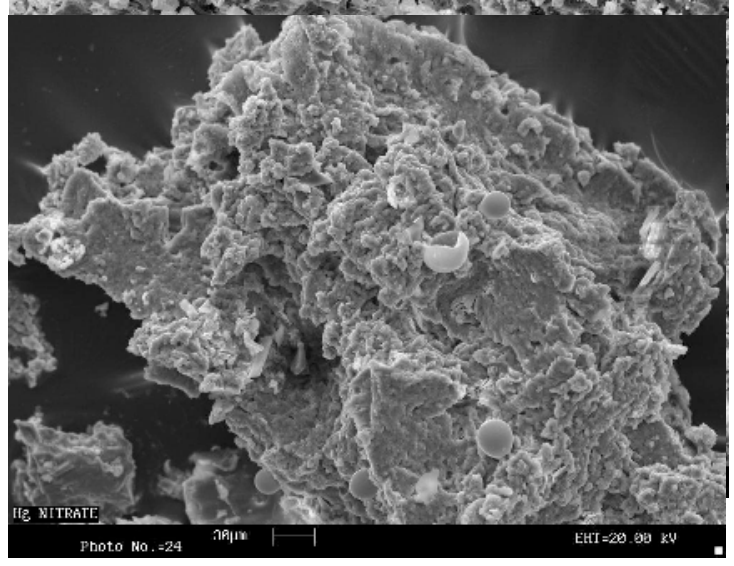

Fig. 2. SEM photographs of metal loaded dehydrated carbon: (a) $\mathrm{Ag}$, (b) $\mathrm{Pd}$, (c) $\mathrm{Hg}_{2} \mathrm{Cl}_{2}$ crystals and (d) mercury microdroplets 